\title{
A VISTA DA SRA. THOMPSON
}

\section{THE VIEW FROM MRS. THOMPSON}

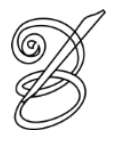

\author{
Autor: \\ David Foster Wallace \\ Traduzido por: \\ Bruno Silva NOGUEIRA* \\ Universidade Federal do Paraná \\ Curitiba, Paraná, Brasil
}

\begin{abstract}
Resumo: David Foster Wallace foi um dos maiores escritores estadunidenses de sua geração, reconhecido como tal desde 1996, com o lançamento de Graça Infinita. Mas seu sucesso não se restringia à produção não-ficcional. Entre seus textos mais conhecidos estão ensaios publicados em revistas e compilados nos volumes A Supposedly Fun Thing I'll Never Do Again, Consider the Lobster, e Both Flesh and Not. Daniel Galera e Daniel Pelizzari traduziram alguns deles em 2012, criando a coletânea Ficando longe do fato de já estar meio que longe de tudo, que buscava ser uma porta de entrada para leitores brasileiros a obras de Wallace, antes da tradução de Graça Infinita. Essa seleção, buscando atrair o leitor, não pôde evitar a omissão de alguns ensaios importantes - entre eles, The View from Mrs. Thompson ${ }^{1}$, cuja tradução apresento. Ele gira em torno da experiência de Wallace ao assistir, pela televisão, de uma pequena cidade no centro dos Estados Unidos, os ataques de onze de setembro. Wallace descreve não só o momento do ataque, mas as experiências e reações que percebe em si e naqueles a seu redor - indicando mais ou menos sutilmente que seu maior medo, talvez, não fosse dos terroristas, mas da reação de seu país e de seus compatriotas a um ataque de tais proporções.
\end{abstract}

Palavras-chave: David Foster Wallace. Literatura estadunidense. Ensaios literários. Escritores estadunidenses. 11 de setembro.

\begin{abstract}
David Foster Wallace was one of the greatest names of American literature in his generation, being recognized as such since the 1996 release of the novel Infinite Jest, widely considered his masterpiece. Still, the work of David Foster Wallace was not restricted to his non-fictional works. Some of his most known and noted texts were essays, which were published in several North-American magazines and later gathered into the successful collections A Supposedly Fun Thing I'll Never Do Again, Consider the Lobster, and Both Flesh and Not. Some essays by Wallace received, in 2012, translations into Portuguese in a collection called Ficando longe do fato de já estar meio que longe de tudo, which published texts that, according to translators Daniel Galera and Daniel Pelizzari, aimed to be an entry point for the Brazilian reader into the work of David Foster Wallace, allowing them to access less complex works from the author before diving into the then unpublished translation of Infinite Jest. Thanks to this selection, which was focused on seducing the reader, and to space constraints, many highly important essays were omitted from the work organized by Galera - among which "The View from Mrs. Thompson", which I translate below. This essay is focused on Wallace's experience as he watched, via television, from a small town in the countryside of the United States, the nine-eleven attacks. Wallace describes not only the moment of the attack, but also the experiences and reactions he notices in himself and in people around him - seeming to indicate, more or less subtly in different parts of the text, that his greatest fear was, perhaps, not fear of terrorism, but of the reaction of his country and his countryman to an attack of such proportions.
\end{abstract}

Keywords: David Foster Wallace. American literature. Literary essays. American writers. September 11.

RECEBIDO EM: 28 de outubro de 2019

ACEITO EM: 25 de novembro de 2019

PUBLICADO EM: março 2020 


\section{A VISTA DA SRA. THOMPSON}

Autor:

David Foster Wallace

Traduzido por:

Bruno Nogueira

\section{LOCAL: BLOOMINGTON, ILLINOIS \\ DATA: 11-13 DE SETEMBRO DE 2001 \\ TEMA: ÓBVIO}

SINÉDOQUE Fiéis à moda meio-oeste, as pessoas de Bloomington não são antipáticas, mas tendem a ser reservadas. Um estranho oferecerá um sorriso caloroso, mas não costuma acontecer aquele conversa-vai-conversa-vem entre desconhecidos em salas de espera ou filas de supermercado. Mas agora, graças ao Horror, há algo a respeito do que falar que supera qualquer inibição, como se de algum jeito todos nós estivéramos lá de pé e tivéssemos visto o mesmo acidente de trânsito. Exemplo: não pude evitar ouvir, na fila do caixa do posto de gasolina (que é meio que o Pão-de-Açúcar dos postos de gasolina/lojas de conveniência localizado central e transversalmente em relação a ambas as pistas de mão única principais e com os melhores preços de tabaco na cidade, ele é um tesouro municipal) entre uma senhora com um avental da Osco e um homem vestindo meio que um colete caseiro feito de uma jaqueta jeans com as mangas cortadas: "Meus filhos eles acharam que era tudo algum filme feito o Independence Day, até que eles começaram a perceber que era o mesmo filme em todos os canais.” (A senhora não disse a idade dos filhos.)

QUARTA-FEIRA Todos hastearam bandeiras. Casas, empresas. É estranho: você nunca vê ninguém colocando a bandeira, mas na manhã de quarta lá estão elas. Bandeiras grandes, pequenas, bandeiras do tamanho oficial de bandeiras. Muitos aqui têm aqueles portabandeiras angulados especiais instalados à parede de casa, aquele tipo cuja base usa quatro parafusos Phillips. Além de milhares daquelas bandeirinhas de palito que normalmente você vê em paradas militares - alguns jardins têm dúzias enfiadas por todo lado na grama, como se elas tivessem brotado de algum jeito na calada da noite. As pessoas das vias mais rurais colocam as bandeirinhas nas caixas do correio ou na beira da estrada. Um número grande de veículos leva bandeiras enfiadas na grade do radiador ou amarradas na antena. Algumas pessoas mais ricas de fato têm mastros; suas bandeiras estão a meia-altura. Não são poucos os 
casarões perto do Franklin Park ou mais além na zona leste que têm até mesmo bandeiras enormes de vários andares penduradas azimuticamente ao longo de suas fachadas. É um mistério completo onde as pessoas encontram bandeiras desse tamanho à venda ou como as colocaram lá, ou quando.

Mesmo o meu vizinho imediato, um contador aposentado e veterano das forças armadas cujo cuidado com a casa e com a grama é nada menos que espetacular, tem um mastro anodizado de tamanho oficial instalado com firmeza em 45 centímetros de cimento reforçado do qual nenhum dos vizinhos gosta muito porque eles acham que atrai raios. Ele diz que há uma etiqueta particular em se colocar uma bandeira à meia-altura: primeiro você deve subi-la até a crista no topo e depois descê-la até a metade. É meio que um insulto se feito de outro modo. A bandeira dele cintila desfraldada ao vento. É com folga a maior bandeira na nossa rua. Também é possível ouvir o vento nos campos de milho ao sul; soa quase como o som de ondas leves ouvidas a duas dunas de distância do mar. A corda do mastro do Sr. Ntem penduricalhos de metal que batem no mastro com um tinido quando está ventando, outra coisa que não agrada muito aos vizinhos. As garagens da casa dele e da minha são quase coladas, e ele está aqui de fora com uma escada dobrável polindo o mastro com algum tipo de óleo especial e um pano de camurça - sem brincadeira - mas é inegável que no sol da manhã o mastro metálico faísca feito a própria ira de Deus.

"Baita bandeira e dispositivo de exibição, Sr. N-."

"Tem que ser. Custou caro."

"Viu todas essas bandeiras por todo lado essa manhã?"

Isso faz ele olhar para baixo e dar um sorriso, mesmo que um pouco amargo. "Não é pouca coisa, né." O Sr. N- não é o que você chamaria de vizinho mais amigável do mundo. $\mathrm{Na}$ verdade, eu só o conheço porque nossas igrejas participam da mesma liga de baseball, onde ele faz o papel de estatístico de seu time com precisão e seriedade. Não somos próximos. Ainda assim ele é o primeiro a quem eu pergunto:

"Sr. $\mathrm{N}-$, me diz uma coisa, imagine que alguém, tipo um estrangeiro ou repórter de TV ou coisa do tipo, viesse até aqui e perguntasse ao senhor para que servem, exatamente, todas essas bandeiras depois de tudo o que aconteceu ontem - o que você acha que responderia?"

"Uai" (depois de alguns momentos em que ele me olhou com o mesmo olhar que normalmente destina a meu gramado), "para mostrar nosso apoio ao que está acontecendo, enquanto americanos." 
No fim das contas a questão é que na quarta-feira havia uma pressão estranha e gradativa para se colocar uma bandeira à frente de casa. Se exibir uma bandeira serve para fazer certo tipo de afirmação, parece que quando se atinge uma certa densidade de bandeiras você está fazendo uma afirmação maior ao não exibir uma. Mesmo assim, não fica muito claro que afirmação seria essa. E se você simplesmente não tiver uma bandeira? Onde foi que todo mundo arrumou essas bandeiras, especialmente essas pequenininhas que se encaixam na caixa de correio? São todas do quatro de julho e as pessoas simplesmente guardam, tipo enfeites de natal? Como elas sabem que têm que fazer isso? Não tem nada nas páginas amarelas sob a palavra Bandeira. A certa altura começa a existir uma tensão real. Ninguém se aproxima ou para o carro e diz, "Ei, por que sua casa não tem uma bandeira?”, mas fica cada vez mais fácil imaginar que estão pensando nisso. Até uma casa parcialmente desmoronada descendo a rua e que todo mundo pensava estar abandonada está com uma daquelas bandeirinhas de palito na grama perto da rua. Descubro que nenhum dos supermercados de Bloomington estoca bandeiras. A grande loja de presentes do centro só tem coisas de Halloween. Só alguns estabelecimentos estão abertos de fato, mas mesmo os lugares fechados 312 exibem algum tipo de bandeira. É quase surreal. Obviamente valia tentar na Associação dos Veteranos, mas o lugar não pode abrir antes do meio dia, se é que abriria (há um bar lá). A moça no balcão do posto de gasolina indica uma certa loja de conveniência horrenda na I-55 chamada IN-Conveniência na qual ela tem bastante certeza de que viu algumas bandeirinhas plásticas nos racks ao fundo onde ficam as bandanas e bonés da NASCAR, mas quando eu chego lá elas já acabaram, levadas por indivíduos desconhecidos. A realidade crua é que não há bandeira alguma nessa cidade. Roubar alguma do jardim de alguém está obviamente fora de questão. Estou de pé sob a luz fluorescente daIN-Conveniência e tenho medo de ir para casa. Tantas pessoas mortas, e o que me leva ao extremo é uma bandeira de plástico. Mas a coisa começa a ficar feia mesmo é quando pessoas começam a se aproximar e perguntar se estou bem e eu tenho que me deitar e dizer que é uma reação ao antialérgico (o que de fato pode acontecer).

... E assim por diante, e em mais uma das estranhas reviravoltas de destino e circunstância provocadas pelo Horror, é o próprio dono do IN-Conveniência(um paquistanês, inclusive) quem me oferece consolo e um ombro e um estranho tipo de compreensão silenciosa, quem me deixa voltar e me sentar no estoque em meio a todos os vícios menores e indulgências que os Estados Unidos podem oferecer para me recompor, e quem, um pouquinho depois, segurando copos de isopor repletos de um tipo estranho de chá perfumado 
ecom muito leite, sugere cartolina e "Pincéis Mágicos", o que explica minha amada e orgulhosamente desfraldada bandeira caseira.

\section{VISTAS AÉREAS E TERRESTRES Todos por aqui recebem o órgão de notícias} local, o Pantagraph, que é profundamente detestado pela maioria dos nativos que eu conheço. Imagine, digamos, um jornal de universidade com bom orçamento e coedição de Bill O'Reilly e Martha Stewart. A capa de quarta-feira diz: ATACADOS! Depois de duas páginas de propaganda você chega no verdadeiro Pantagraph. Um sic adiantado para tudo que segue. As maiores manchetes de quarta-feira são: CIDADÃOS ASSUSTADOS PASSAM MUITAS EMOÇÕES; CLERO COM BRAÇO ABERTO PARA AJUDAR PESSOAS A LIDAR COM TRAGÉDIA; PROFESSOR DA ISU: B-N NÃO É ALVO PROVÁVEL; PREÇOS DE GASOLINA NOS ARESEM POSTOS; AMPUTADO DÁ DISCURSO INSPIRADOR. Há uma foto de meia página de um aluno da Escola Secundária Católica Central de Bloomington rezando o rosário como resposta ao Horror, o que significa que algum fotógrafo da equipe entrou e jogou o flash no rosto de uma criança traumatizada que rezava. A coluna de comentários do leitor em 12/09 começa assim: "A carnificina que vimos pelos olhos das lentes em Nova York e Washington D.C., mesmo agora se parece com um filme para maiores produzido em Hollywood."

Bloomington é uma cidade de 65.000 pessoas na região central de um estado que é extremamente, enfaticamente plano, de modo que é possível ver os pontos salientes da cidade de muito longe. Três rodovias interestaduais convergem para cá, bem como várias linhas de trem. A cidade está quase exatamente no meio do caminho entre Chicago e St. Louis, e suas origens envolvem ser um entreposto férreo importante. Bloomington é o local de nascimento de Adlai Stevenson e a cidade natal putativa do Coronel Blake de $M * A * S * H$. A cidade tem uma gêmea menor, a cidade Normal, que foi construída ao redor de uma universidade pública e é inteiramente uma outra história. As duas cidades juntas somam cerca de 110.000 pessoas.

Em relação a outras cidades do meio-oeste, a única característica de destaque de Bloomington é sua prosperidade. Ela é virtualmente à prova de recessão. Um pouco disso se deve às fazendas do condado, que têm fertilidade de nível internacional e cujo acre é tão caro que um civil não consegue nem ficar sabendo quanto custa. Mas Bloomington também abriga a sede nacional da State Farm, que é a deusa sombria do mercado de seguros nos Estados Unidos, e em todos os sentidos práticos é a dona da cidade, e graças a ela a região leste de Bloomington é hoje repleta de complexos de vidro filmado e construções sob medida e tem 
uma estrada de seis vias largas com shoppings e franquias que estão matando o comércio no centro antigo, além de uma divisão cada vez maior entre as duas classes e culturas básicas da cidade, simbolizadas tão bem pelo SUV e pela caminhonete pick-up, respectivamente. ${ }^{3} \mathrm{O}$ inverno aqui é um merda sem piedade, mas nos meses mais quentes Bloomington se parece muito com uma comunidade à beira-mar, com a exceção de que o oceano é de milho, e seu crescimento esteroidal se estende até a curva da terra em todas as direções. A cidade em si fica intensamente verde no verão — ruas banhadas pela sombra das árvores e jardins berrantes nas casas e em dezenas de parques que parecem recém-saídos do cabeleireiro e campos de baseball e de golfe que você quase precisa proteger os olhos para olhar, e gramados fertilizados largos e sem daninhas cuidadosamente cuidados com ferramentas especiais de modo a se perfilar perfeitamente alinhados à calçada. ${ }^{4}$ Para ser sincero, é um pouco perturbador, especialmente no alto verão, quando ninguém sai e todo esse verde simplesmente fica lá no calor e ferve.

Assim como a maioria das cidades do meio-oeste, B-N está coalhada de igrejas: quatro páginas inteiras da lista telefônica. Tudo desde a Unitária até os Pentecostais e seus olhos 314 esbugalhados. Tem até uma igreja para agnósticos. Mas à exceção de igrejas — além de eu acho as paradas militares típicas, fogos, e uns poucos festivais do milho — não há muitos eventos públicos da comunidade. Todo mundo tem sua família e vizinhos e circulozinho apertado de amigos. As pessoas são reservadas (o termo que os nativos usam para falar de conversas rápidas é visitar). Basicamente todos jogam baseball ou golfe ou fazem churrasco, e assistem aos filhos jogarem futebol, e de vez em quando assistem a um filme da moda.

...E assistem quantidades massivas, impressionantes de TV. E eu não estou falando só das crianças. No que diz respeito a Bloomington e o Horror é importante ter em mente que a realidade - qualquer absorção de um mundo maior pelos sentidos - é majoritariamente televisual. O horizonte de Nova York, por exemplo, é reconhecível daqui como de qualquer outro lugar, mas esse horizonte é reconhecível a partir de imagens da TV. A TV também é um fenômeno social maior que na Costa Leste, onde na minha experiência as pessoas estão quase constantemente saindo de casa para encontrar outras pessoas cara a cara em lugares públicos. Aqui as pessoas não tendem tanto a se encontrar em festas ou coquetéis per se - o que se faz em Bloomington é se encontrar com todos na casa de alguém e assistir alguma coisa.

Em Bloomington, portanto, ter uma casa sem TV é se tornar meio que uma presença constante do tipo Kramer na casa dos outros, um convidado perpétuo de pessoas que não conseguem entender muito bem porque alguém não teria uma TV mas que respeitam 
totalmente sua necessidade de assistir TV, e que vão lhe oferecer acesso à TV deles do mesmo jeito instintivo como se curvariam para lhe oferecer a mão se você caísse na rua. E isso é especialmente verdadeiro para situações de crise, do tipo você precisa ver, como a eleição de 2000 ou o Horror dessa semana. Tudo o que você precisa fazer é telefonar para alguém que você conhece e dizer que não tem uma TV: "Menino do céu, vem pra cá."

TERÇA-FEIRA Talvez haja dez dias por ano em que Bloomingtonfica linda, e 11 de setembro é um deles. $\mathrm{O}$ ar está claro e temperado e maravilhosamente seco depois de várias semanas do que parecia ser a sensação de morar no sovaco de alguém. A colheita está prestes a começar de verdade, época na qual a quantidade de pólen no ar da região é a maior do ano, e boa parte dos moradores da cidade está chapada de antialérgico, o que como você provavelmente sabe tende a dar à manhã uma espécie de qualidade onírica, subaquática. Temporalmente falando, nosso fuso é uma hora atrasado em relação à Costa Leste. Às 8:00, todos que tem um trabalho já estão nele, e praticamente todos os outros estão em casa tomando café e assoando o nariz e assistindo Today ou algum programa matutino de alguma outra rede de televisão que transmita (desnecessário dizer) de Nova York. Na terça-feira às 8:00 eu estava no chuveiro, tentando ouvir um post-mortem do time dos Bears na Rádio Esportiva WSCR de Chicago.

A igreja que eu frequento fica na região sul de Bloomington, perto da minha casa. A maioria das pessoas que eu conheço bem o suficiente para perguntar se eu posso ir à casa delas assistir TV são membros da minha igreja. Não é uma dessas igrejas onde se diz o nome de Jesus o tempo todo ou se fica falando do Fim dos Tempos, mas é bastante séria, e as pessoas na congregação acabam se conhecendo bem e ficando bem próximas. Até onde eu sei, todos os seus membros são nativos da região. A maioria é da classe trabalhadora ou se aposentou dela. Alguns são donos de pequenos estabelecimentos. Há um número razoável de veteranos e/ou pessoas com filhos no exército ou - especialmente - na reserva militar, porque é o jeito que muitas dessas famílias encontra de pagar a universidade.

A casa na qual eu acabo sentado com shampoo no meu cabelo assistindo a maior parte do Horror que se desdobra pertence à Sra. Thompson, que é uma das mulheres de setenta e quatro anos mais legais do mundo e aquele tipo específico de pessoa que mesmo que o telefone esteja ocupado você sabe que pode ir direto para lá. Ela mora a pouco mais de um quilômetro da minha casa, atravessando uma área para trailers. As ruas não estão movimentadas, mas não estão tão vazias quanto vão ficar. A casa da Sra. Thompson tem um 
andar e é pequena e imaculada e na Costa Leste seria chamada de bangalô e no sul de Bloomington é chamada de casa. A Sra. Thompson é membro e líder da congregação há tempos, e sua sala de estar tende a ser meio que um ponto de encontro. Ela também é a mãe de um dos meus melhores amigos aqui, F-, que foi soldado no Vietnam e levou um tiro no joelho e agora trabalha como empreiteiro instalando todo tipo de lojas de franquias em shoppings. Ele está no meio de um divórcio (longa história) e morando com a Sra. T. enquanto o tribunal decide o destino de sua casa. F- é um desses veteranos que não fala sobre a guerra nem é membro da Associação de Veteranos, mas às vezes parece tomado por uma preocupação sombria e vai sozinho e sem alarde para o campo no fim de semana do Memorial Day, e dá para perceber que ele carrega alguma coisa pesada consigo. Como a maioria das pessoas que trabalha em construção, ele acorda muito cedo e já saiu há algum tempo quando eu chego na casa de sua mãe, o que acontece imediatamente depois que o segundo avião atinge a Torre Sul, ou seja, por volta de umas 8:10.

Pensando agora, o primeiro sinal possível de estar em choque foi o fato de que eu não toquei a campainha e simplesmente fui entrando, o que normalmente eu nunca faria aqui. 316 Graças em parte aos contatos de trabalho do filho, a Sra. T. tem uma TV Philips de tela plana e quarenta e duas polegadas na qual Dan Rather acaba de aparecer por um segundo só de camisa e com o cabelo um pouco bagunçado. (As pessoas de Bloomington parecem dar uma preferência esmagadora à CBS News; não fica claro por quê.) Muitas outras senhoras da igreja já estão aqui, mas eu não sei se eu cumprimentei alguém porque me lembro de que quando eu entrei todos estavam encarando transfixados uma das pouquíssimas imagens que a CBS passou repetidas vezes na história, que era uma tomada distante em ângulo aberto da Torre Norte com sua estrutura metálica exposta em chamas, e de pequenos pontos se separando da construção e se movendo para baixo pela fumaça, e que um zoom espasmódico da tomada mostrou então serem pessoas reais de ternos e gravatas e saias com seus sapatos caindo conforme eles caíam, alguns deles se segurando nas bordas ou em vigas e então se soltando, de cabeça pra baixo ou se debatendo conforme caíam e um casal que quase parecia (inverificável) estar se abraçando conforme caíam aqueles tantos andares e voltavam a se transformar em pontos conforme a câmera então repentinamente reduziu o zoom voltando a uma vista mais panorâmica — não tenho nenhuma ideia de quanto tempo essa imagem durou - depois do quê a boca de Dan Rather pareceu se movimentar por um segundo antes que qualquer som emergisse, e todos na sala se sentaram e olharam uns para os outros com expressões que pareciam ao mesmo tempo infantis e terrivelmente antigas. Acho que uma ou 
duas pessoas emitiram algum som. Não sei bem o que mais dizer. Parece grotesco dizer que se ficou traumatizado por uma imagem em vídeo enquanto as pessoas no vídeo estavam morrendo. Alguma coisa na queda dos sapatos tornava as coisas piores. Acho que as senhoras mais velhas lidaram com a situação melhor que eu. E em seguida a beleza horrenda na reprise da cena do segundo avião atingindo a torre, seu azul e prata e preto e laranja espetaculares, enquanto mais pontos semoventes caíam. A Sra. Thompson estava em sua cadeira, que é uma cadeira de balanço com travesseiros floridos. A sala tem duas outras cadeiras, e um sofá de veludo cotelê tão grande que $\mathrm{F}$ - e eu tivemos que tirar a porta das dobradiças para conseguir levar para dentro da casa. Todos os lugares estavam ocupados, o que significa umas cinco ou seis outras pessoas, eu acho, a maioria mulheres, todas acima dos cinquenta, e havia mais vozes na cozinha, uma das quais soava muito abalada e pertencia à psicologicamente delicada Sra. R-, que eu não conheço muito bem mas cuja reputação como uma grande beleza local do passado ainda é lembrada. Muitas das pessoas são vizinhos da Sra. T, e algumas ainda estão em seus robes, e em diversos momentos algumas pessoas saíam para ir até suas casas e usar o telefone e voltar, ou simplesmente saíam (uma moça mais nova foi pegar seus filhos na escola), e outras pessoas chegavam. Num certo momento, por volta do ponto em que a Torre Sul caía sobre si mesma de um modo que parecia tão perfeito (eu me lembro de pensar que ela estava caindo assim como uma mulher elegante cai, mas foi o normalmente inútil e irritante filho da Sra. Bracero, Duane, que afirmou que parecia mais com um lançamento de foguete da NASA que você pegasse e rodasse ao contrário, o que depois de reassistir várias vezes realmente parece um comentário certeiro), havia pelo menos uma dúzia de pessoas na casa. Havia pouca luz na sala porque no verão por aqui todos sempre mantêm suas cortinas abaixadas. $^{5}$

É normal não se lembrar de coisas muito bem depois de uns poucos dias, ou pelo menos da ordem em que aconteceram? Eu sei que em algum momento e por algum tempo eu ouvi o som lá fora de um vizinho cortando a grama, o que pareceu absolutamente bizarro, mas eu não me lembro se alguém disse algo a respeito. Algumas vezes parecia que ninguém dizia nada e algumas como se todos estivessem falando ao mesmo tempo. Também havia muita atividade telefônica. Nenhuma dessas mulheres usa celular (o Duane tem um pager cuja função não é clara), então só temos o velho telefone à parede da cozinha da Sra. T. Não que todas as chamadas tenham um motivo racional. Um efeito colateral do Horror foi um desejo irresistível de se telefonar para todos que você ama. Descobrimos bem cedo que não se conseguia falar com ninguém em Nova York - discar 212 levava apenas a um estranho som 
rascante. As pessoas ficavam pedindo permissão à Sra. T. até que ela disse pra eles pararem com isso e pelo amor de Deus usarem o telefone de uma vez. Algumas das mulheres conseguiram falar com seus maridos, que aparentemente estavam reunidos ao redor de TVs e rádios em seus diversos locais de trabalho; por algum tempo os chefes ficaram chocados demais para mandar as pessoas para casa. A cafeteira da Sra. T. está ligada, mas outro sinal da crise é que se você quiser beber café precisa pegar você mesmo - normalmente ele meio que se materializa. Eu me lembro de ver a segunda torre caindo da porta da cozinha e me confundir pensando que fosse um replay da queda da primeira torre. Outro problema da rinite alérgica é que você nunca consegue ter certeza absoluta se alguém está chorando, mas ao longo das duas horas com as primeiras transmissões do Horror, com reportagens bônus da queda do avião na Pensilvânia e de Bush sendo levado para um bunker do Comando Aéreo e de um carro bomba que explodiu em Chicago (esta última posteriormente revogada), praticamente todo mundo chora ou chega bem perto, de acordo como suas habilidades relativas. A Sra. Thompson fala menos que quase todos. Eu não acho que ela tenha chorado, mas, ainda assim, ela não se balança na cadeira como de hábito. A morte de seu primeiro 318 marido supostamente foi repentina e aterradora, e eu sei que em alguns momentos durante a guerra $\mathrm{F}$ - estave no fronte e ela não recebia notícias por várias semanas consecutivas e não sabia sequer se ele estava vivo. A principal contribuição de Duane Bracero é reiterar continuamente o quanto aquilo tudo parece um filme. Duane, que tem pelo menos vinte e cinco mas continua vivendo na casa dos pais enquanto teoricamente estuda para o trabalho de soldador, é uma dessas pessoas que sempre usam camisetas camufladas e botas de paraquedista mas nunca sonharia em de fato se alistar (assim como, para ser honesto, eu também não). Além disso ele não tirou o boné, que faz propaganda de alguma coisa chamada SLIPKNOT, dentro da casa da Sra. Thompson. Sempre parece importante ter alguém para se odiar nas proximidades.

No fim das contas a causa da crise nervosa da pobre e delicada Sra. R - é que ela tem ou uma sobrinha-neta ou primo distante que está fazendo algum tipo de estágio na Time, Inc., no prédio da Time-Life ou seja lá como se chama, um prédio a respeito do qual a única coisa que a Sra. $\mathrm{R}$ - e todos os outros com quem ela conseguiu falar só sabem que é um arranhacéus vertiginosamente alto em algum lugar de Nova York, e ela está fora de si de preocupação, e outras duas senhoras ficam o tempo todo aqui segurando suas duas mãos e tentando decidir se chamam ou não seu médico (a Sra. R - tem um histórico), e eu acabo fazendo o que é praticamente a única coisa útil que faço o dia todo ao explicar para a Sra. R- 
onde o centro de Manhattan fica. Depois do quê eu percebo que nenhuma das pessoas com quem estou assistindo o Horror - nem mesmo as duas senhoras que foram assistir ao Cats em algum tipo de excursão feita pela igreja em 1991 - tem sequer a mais vaga noção de como Nova York se distribuiu e não sabe, por exemplo, o quão radicalmente distantes o Distrito Financeiro e a Estátua da Liberdade ficam um do outro; para mostrar isso a elas é preciso apontar para o oceano que aparece na base da tela da linha do horizonte que elas conhecem tão bem (pela TV).

A pequena lição meia-boca de geografia é o começo de um sentimento de alienação em relação a essas boas pessoas que cresce em mim ao longo de todo esse trecho do Horror em que as pessoas fogem dos detritos e da poeira. Essas senhoras não são estúpidas, ou ignorantes. A Sra. Thompson consegue ler em latim e espanhol, e a Srta. Voigtlander é uma fonoaudióloga que certa vez me explicou que o estranho som de deglutição que faz com que o apresentador da NBC Tom Brokaw seja tão distrativo é chamado de $L$ glotal. Foi uma das senhoras na cozinha dando apoio à Sra. $\mathrm{R}$ - quem apontou o fato de que 11 de setembro é o aniversário dos Acordos de Camp Davis, o que com certeza era novidade para mim.

O que essas senhoras de Bloomington são, ou começam a parecer a meus olhos, é inocentes. Nesse cômodo há o que pareceria aos americanos normais ser uma acentuada, uma surpreendente falta de cinismo. Ninguém pensa em comentar, por exemplo, que talvez seja um pouco estranho que os âncoras de todas as três redes de televisão estão só de camisa, ou considera a possibilidade que o cabelo bagunçado de Dan Ratherpode não ser inteiramente acidental, ou que a repetição constante de imagens terríveis pode não ser unicamente para espectadores que tenham acabado de ligar a televisão e ainda não viram. Nenhuma dessas senhoras parece notar que os estranhos olhinhos sem brilho do presidente parecem se aproximar cada vez mais um do outro durante o discurso gravado por ele, ou que algumas de suas frases parecem plagiar quase identicamente as falas de Bruce Willis (no papel de um maluco de extrema direita, é bom lembrar) no filme Nova York Sitiada alguns anos atrás. Nem que pelo menos um pouco da consumada estranheza de assistir ao desdobramento do Horror é perceber o quanto várias tomadas e cenas espelharam os roteiros de tudo desde Duro de Matar I-III até Força Aérea Um. Ninguém é nem de perto antenado o suficiente para cravar a óbvia reclamaçãozinha pós-moderna esperta: Já Vimos Isso Antes. Em vez disso, o que eles fazem é se sentar juntos e se sentir muito, muito mal, e rezar. Ninguém no grupo da casa da Sra. Thompson seria tão indigesto a ponto de tentar fazer todos rezarem em voz alta ou formar um círculo de orações, mas ainda assim é possível perceber o que estão fazendo. 
Não se engane, isso é uma coisa majoritariamente boa. Força você a pensar e a fazer coisas que normalmente não faria sozinho, como por exemplo observar o discurso e rezar, em silêncio mas com fervor, para que você esteja errado sobre o presidente, que sua visão dele possa estar distorcida e que ele de fato tenha bem mais inteligência e substância do que você pensa e não seja apenas um golem sem alma ou nexo de interesses corporativos vestindo um terno mas sim um estadista com coragem e probidade e... e é bom, é bom rezar assim. Mas é um pouco solitário ter que fazê-lo. Ficar ao redor de pessoas verdadeiramente decentes, inocentes, pode ter seu peso. Eu não estou nem por um momento tentando sugerir que todos que eu conheço em Bloomington são como a Sra. Thompson (seu filho F- não é, p. ex., embora seja uma pessoa fantástica). Estou tentando, em vez disso, explicar como um pouco do horror do Horror é saber, no fundo do coração, que a versão dos Estados Unidos que os homens nos aviões odiavam tanto, seja qual for, era muito mais a minha versão, e a versão do F-, e do pobre e detestável Duane, que a versão dessas senhoras.

\section{1}

\footnotetext{
* Bruno Silva NOGUEIRA - Graduado em Letras Português/Espanhol (2015) pela Universidade Federal do Triângulo Mineiro. Mestrando em Letras pela Universidade Federal do Paraná. Universidade Federal do Paraná, Setor de Ciências Humanas, Programa de Pós-Graduação em Letras. Curitiba, Paraná, Brasil.

Currículo acadêmico: http://lattes.cnpq.br/4148727609962634

ORCID: https://orcid.org/0000-0001-8895-6645

E-mail: bsnoguera@gmail.com
}

${ }^{1}$ The David Foster Wallace Literary Trust \% Hill Nadell Literary Agency (concedente) autorizou a tradução de The View from Mrs. Thmpson, de autoria de David Foster por pare do tradutor Bruno Nogueira (licenciado), e sua publicação na revista Belas Infiéis em 19 de setembro de 2019. Contudo, a concedente pode revogar a permissão e uso do trabalho em qualquer momento caso a obra seja vendida para alguma editora brasileira, devendo a publicação ser retirada em até cinco dias úteis após pedido à revista ou ao licenciado.

${ }^{2}$ Mais: outras respostas selecionadas dentre os vários momentos durante a caça-à-bandeira do dia quando as circunstâncias permitiram que a pergunta fosse feita sem que eu parecesse um sabe-tudo ou um doido:

"Pra mostrar que somos americanos e não vamos abaixar a cabeça pra ninguém";

"É um pseudo-arquétipo clássico, um signo reflexivo concebido para se adiantar à função crítica e negála" (estudante de pós);

"Por orgulho."

"O que elas fazem é simbolizar a união e que estamos todos juntos em apoio às vítimas nessa guerra e que eles mexeram com a pessoa errada,meu irmão."

${ }^{3}$ Pace a impressão de algumas pessoas, o sotaque nativo por aqui não é tão sulino quanto simplesmente rural. Os transplantes corporativos da cidade, por sua vez, não têm sotaque nenhum - nas palavras da Sra. Bracero, os funcionários da StateFarm "soam como gente da TV."

${ }^{4}$ As pessoas aqui são profunda, profundamente ligadas ao cuidado com o gramado; meus vizinhos mesmo cortam a grama com a mesma frequência com que se barbeiam.

${ }^{5}$ A sala da Sra. Thompson também é prototipicamente uma sala da classe trabalhadora de Bloomington: janelas com vidros duplos, cortinas brancas com saia da Sears, relógios de catálogo com desenhos de pato ao fundo, rack para revistas de imitação de madeira com o Guia de Escrita de Chicago e a Reader'sDigest, estantes de livros embutidas usadas para exibir pequenas estatuetas e porta-retratos com fotos de parentes e suas famílias. Há dois paninhos promocionais com o poema Desiderata e com a Oração de São Francisco, tapetinhos de crochê em todas as cadeiras boas, e carpetes de uma ponta a outra, tão grossos que você não enxerga seu pé (as pessoas tiram os sapatos à porta — o mínimo em termos de boa educação). 